\title{
Notes on the vocalizations of Spotted Antpitta (Hylopezus macularius)
}

\section{Peter Boesman}

In the following we briefly analyze and compare voice of the different races of Spotted Antpitta (Hylopezus macularius). We also try to quantify the extent of any vocal differences using the criteria proposed by Tobias et al. (2010), as a support for taxonomic review. We have made use of sound recordings available on-line from Xeno Canto (XC).

This case was studied in Carneiro et al. (2012). They indicate the presence of 4 distinct groups, which redefines present treatment of subspecies (in the following I use the proposed names and corresponding distribution). In table 1 of this paper a series of measurements (average + standard deviation) is given for the loudsong. Pair-wise effect sizes (ES) can thus be calculated for the basic sound parameters:

paraensis vs. whittakeri:

\begin{tabular}{|c|c|}
\hline \# of notes & ES 5.4 -> score 3 \\
\hline song length & ES 1.2 -> score 1 \\
\hline pace & ES 4.99 -> score 2 \\
\hline note shape & different $->$ score 1-2 \\
\hline \multicolumn{2}{|c|}{ paraensis vs. dilutus } \\
\hline \# of notes & ES 0.0 -> score 0 \\
\hline song length & ES 1.85 -> score 1 \\
\hline pace & ES 1.96 -> score 1-2 \\
\hline note shape & different $->$ score 1-2 \\
\hline
\end{tabular}

paraensis vs. macularius

$\begin{array}{ll}\text { \# of notes } & \text { ES } 0.0->\text { score } 0 \\ \text { song length } & \text { ES } 0.0->\text { score } 0 \\ \text { pace } & \text { ES } 0.0->\text { score } 0 \\ \text { note shape } & \text { different }->\text { score } 1-2\end{array}$

whittakeri vs. dilutus

\# of notes

song length

pace

note shape
ES $6.25 \rightarrow$ score 3

ES $2.1 \rightarrow$ score 2

ES 5.8 -> score 3

different -> score 1-2

whittakeri vs. macularius

\# of notes

song length

pace

note shape
ES 4.57 -> score 2

ES 1.09 -> score 1

ES 4.24 -> score 2

different -> score 1-2 

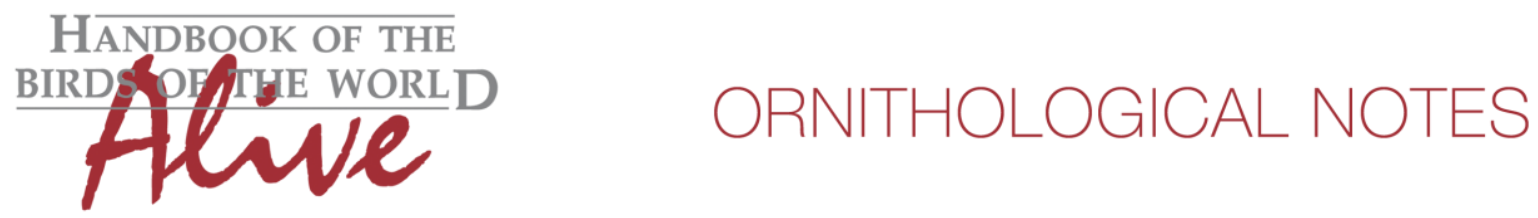

dilutus vs. macularius

$\begin{array}{ll}\text { \# of notes } & \text { ES } 0.0->\text { score } 0 \\ \text { song length } & \text { ES } 1.87 \text { - > score } 1 \\ \text { pace } & \text { ES } 1.88 \text { - score } 1 \\ \text { note shape } & \text { almost identical }->\text { score } 0\end{array}$

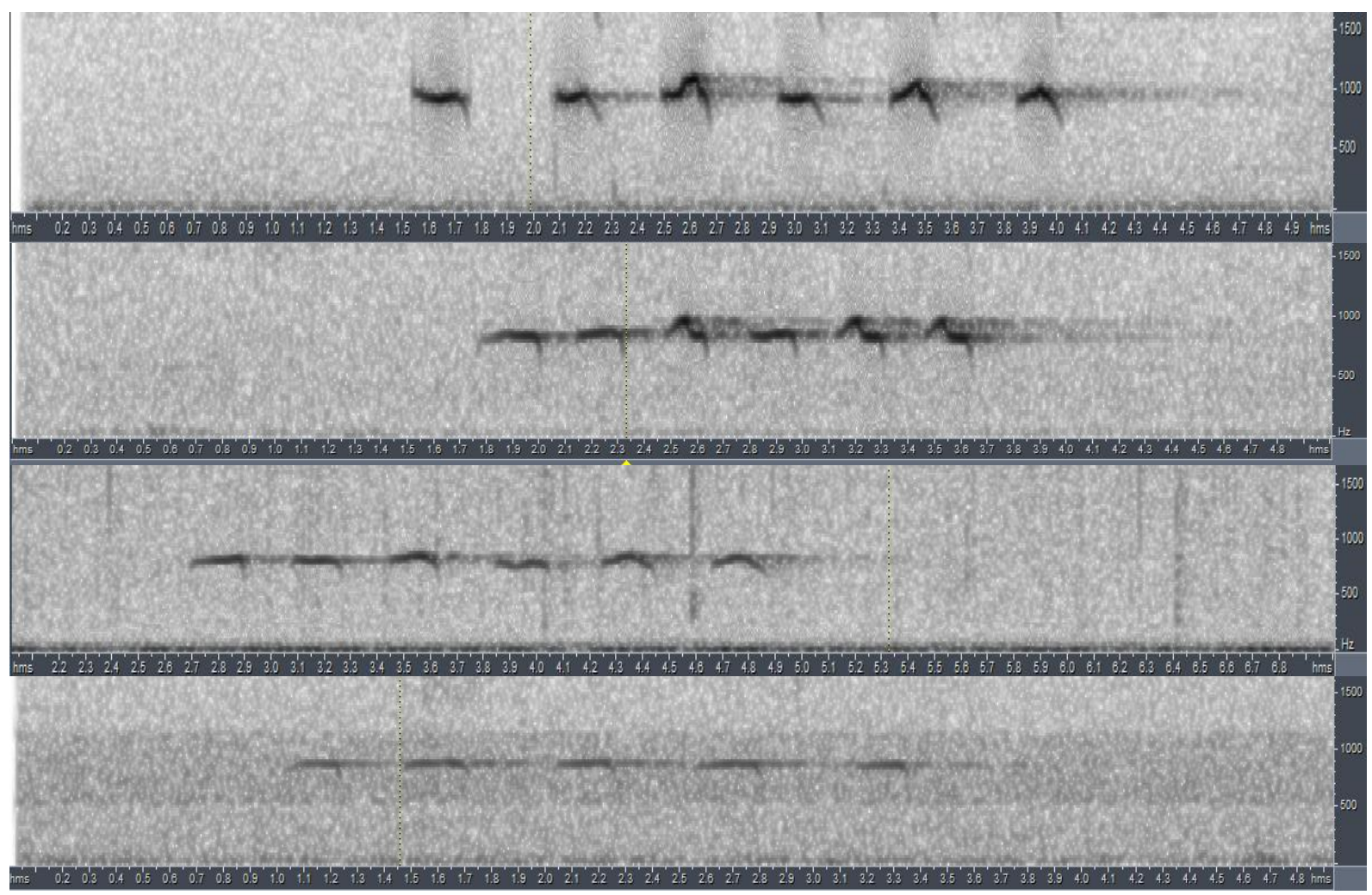

Figure 1: from top to bottom: macularius, dilutus, paraensis and whittakeri

\section{Discussion of vocal differences}

The authors consider dilutus and macularius not to be sufficiently divergent to consider them as two distinct BSC species. The remaining 3 groups are proposed as distinct species, although the authors indicate they don't meet the 3-differences yardstick proposed by Isler et al. 1998). SACC confirmed surprisingly 'strong vocal evidence' as an important reason for elevating these to species rank http://www.museum.Isu.edu/ Remsen/SACCprop622.htm .

The score for vocal difference between dilutus vs macularius is 2 . The authors themselves propose to treat these as a single species. This means however that dilutus/macularius should be grouped, and previous scores should be reviewed in comparison with this clustered group. 

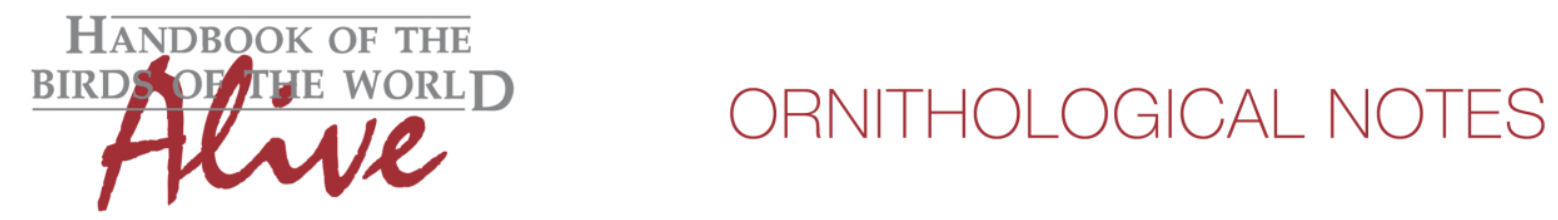

\author{
paraensis vs. dilutus/macularius \\ \# of notes score 0 \\ song length score 0 \\ pace score 1 \\ note shape different $->$ score 1-2 \\ whittakeri vs. dilutus/macularius \\ \# of notes score 2-3 \\ song length score 1-2 \\ pace score 2-3 \\ note shape different $->$ score 1-2
}

It would seem that the vocal difference of paraensis vs. dilutus/macularius is quite small as well: total score 2-3 (also confirmed by listening to recordings of both groups: they are identifiable but difference is small (Fig. 1).

Race whittakeri on the other hand retains a score of about 5 vs. the two other groups (even if paraensis would also be lumped with dilutus/macularius, which would be a bit awkward distribution-wise). Main differences are that song consists typically of 5 notes rather than 6 , delivered at a slower pace, resulting in a marginally longer song strophe.

We can thus conclude that the proposed recognition of 4 races is supported by moderate scores (folllowing Tobias 2010) for vocal differences, but only the newly defined race whittakeri stands out.

This note was finalized on 23 rd June 2015 , using sound recordings available on-line at that moment. We would like to thank in particular the sound recordists who placed their recordings for this species on XC: Nick Athanas, Peter Boesman, David Edwards, Sidney Dantas, Patrick Ingremeau, Jon King, Dan Lane, Alex Lees, Gabriel Leite, Hans Matheve, Luiz Mazzoni, Nargila Moura, Alexandre Renaudier, Micah Riegner, Fabrice Schmitt, Andrew Spencer and Charlie Vogt.

\title{
References
}

Carneiro, L. S., Gonzaga, L. P., Rêgo, P. S., Sampaio, I., Schneider, H., and Aleixo, A. (2012). Systematic revision of the Spotted Antpitta (Grallariidae: Hylopezus macularius), with description of a cryptic new species from Brazilian Amazonia. Auk 129: 338-351.

Isler, M. L., P. R. Isler, and Whitney B. M. (1998). Use of vocalizations to establish species limits in antbirds (Passeriformes: Thamnophilidae). Auk 115:577-590. 


\section{Recommended citation}

Boesman, P. (2016). Notes on the vocalizations of Spotted Antpitta (Hylopezus macularius). HBW Alive Ornithological Note 73. In: Handbook of the Birds of the World Alive. Lynx Edicions, Barcelona. (retrieved from http://www.hbw.com/node/931961 on 17 May 2016). 